\title{
Ukrainian early (pre-1850) historical weather observations
}

\author{
Oleg Skrynyk $^{1,2}$ (i) | Jürg Luterbacher ${ }^{3}$ (D) | Rob Allan $^{4}$ (D) | Dmytro Boichuk ${ }^{1,5}$ (i) | \\ Vladyslav Sidenko $^{1}$ (i) | Olesya Skrynyk ${ }^{1,6}$ (i) \\ Angelika Palarz $^{7}$ (D) | Dmytro Oshurok ${ }^{1}$ \\ Elena Xoplaki $^{8,9}$ (i) | Volodymyr Osadchyi ${ }^{1}$
}

\author{
${ }^{1}$ Ukrainian Hydrometeorological Institute, \\ Kyiv, Ukraine \\ ${ }^{2}$ Center for Climate Change C3, Universitat \\ Rovira i Virgili, Tarragona, Spain \\ ${ }^{3}$ Science and Innovation Department, World \\ Meteorological Organization (WMO), \\ Geneva, Switzerland \\ ${ }^{4}$ ACRE/Met Office Hadley Centre, Exeter, \\ UK \\ ${ }^{5}$ Taras Shevchenko National University of \\ Kyiv, Kyiv, Ukraine \\ ${ }^{6}$ National University of Life and \\ Environmental Sciences of Ukraine, Kyiv, \\ Ukraine \\ ${ }^{7}$ Department of Climatology, Jagiellonian \\ University, Kraków, Poland \\ ${ }^{8}$ Department of Geography, Climatology, \\ Climate Dynamic and Climate Change, \\ Justus Liebig University Giessen, Giessen, \\ Germany \\ ${ }^{9}$ Center of International Development and \\ Environmental Research, Justus Liebig \\ University Giessen, Giessen, Germany

\section{Correspondence} \\ Oleg Skrynyk, Ukrainian \\ Hydrometeorological Institute, 37 Nauky \\ Avenue, Kyiv, 03028, Ukraine.
}

\begin{abstract}
In this paper, we describe the results of a climate data rescue (DARE) activity conducted at the Ukrainian Hydrometeorological Institute (Kyiv, Ukraine) in cooperation with the Justus Liebig University Giessen (Giessen, Germany), the World Meteorological Organization (WMO) and Met Office Hadley Centre (Exeter, United Kingdom). The focus of our work is on pre-1850 sub-daily meteorological observations conducted on the territory of modern Ukraine. Data from eight stations (stored in special hard copy tables/books, with handwritten records) have been digitized during the DARE process, resulting in 291,103 rescued values in total. More than half of this number $(165,980, \sim 57 \%)$ are related to air temperature data, 124,376 data values ( $42.7 \%$ ) concern atmospheric pressure records and 747 values $(\sim 0.3 \%)$ are precipitation data. Simple quality control of the digitized data has been conducted, including an intercomparison between stations as well as comparison with monthly temperature data previously digitized from other paper sources. The quality control procedures revealed fairly good agreement between rescued time series on the monthly time scale as well as with the monthly data from independent sources. However, several periods for a few stations should be used with caution due to relatively large discrepancies that were found. The rescued digital database can be used for extreme value analysis for the pre-1850 period in comparison with today's climate, regional climatological studies and will be used for future Reanalysis. In addition, for the first time, we
\end{abstract}

\section{Dataset}

Identifier: https://doi.org/10.15407/uhmi.report.01

Creator: Oleg Skrynyk, Jürg Luterbacher, Rob Allan, Dmytro Boichuk, Vladyslav Sidenko, Olesya Skrynyk, Angelika Palarz, Dmytro Oshurok, Elena Xoplaki, Volodymyr Osadchyi

Title: Ukrainian early (pre-1850) historical weather observations

Publisher: Ukrainian Hydrometeorlogical Institute (UHMI)

Publication year: 2020

Resource type: Dataset

Version: 1.0

This is an open access article under the terms of the Creative Commons Attribution License, which permits use, distribution and reproduction in any medium, provided the original work is properly cited.

๑) 2020 The Authors. Geoscience Data Journal published by Royal Meteorological Society and John Wiley \& Sons Ltd. 
Emails: skrynyk@uhmi.org.ua; oleg.

skrynyk@urv.cat show that subdaily temperature from Kyiv during 'the year without summer' 1816 in Western and Central Europe were not anomalous in this part of Eastern Europe.

\section{K E Y W O R D S}

air temperature, atmospheric pressure, data rescue (DARE), pre-1850 meteorological observations, Ukraine, Tambora

\section{I INTRODUCTION}

Detection and quantitative assessment of the recent climate change on global and regional scales is mainly based on data from instrumental measurements conducted on meteorologi$\mathrm{cal} /$ climatological stations all over the world (Hartmann et al., 2013). The records of such measurements are an extremely important source of information related to variations in the state of the atmosphere. Longer and more detailed records are the most valuable for climate research and applications through assessing long-term trends, variability and extremes and comparing historic and current conditions that researchers can build robust and consistent picture of what is happening across the planet. However, not all climatological data (derived from meteorological measurements/observations) are available to researchers (e.g. Brönnimann et al., 2019), since their oldest part often still exists only in hard copy form that need to be rescued, digitised and quality controlled first. Rescue, recovery, digitization and quality control of historical meteorological/climatological data is of extraordinary importance for the climatological community (e.g. Brázdil et al., 2010; Allan et al., 2011; Kwok, 2017; Brönnimann et al., 2018a, b; Brönnimann et al., 2019; Brönnimann and Wintzer, 2019; Wilkinson et al., 2019; Brunet et al., 2020; Craig and Hawkins, 2020). Data rescue activities include the ongoing process of preserving data that are of risk of being lost due to deterioration of the medium and digitizing current and past data into computer compatible form for easy access (I-DARE, 2019).

It is also worth noting that modern climate research, applications and services seek to operate with information (including its historical part) regarding climate variability at a high temporal resolution. Therefore, daily or even sub-daily (original measurements/observations) meteorological data are currently becoming the main base for climate research, extreme analysis and impact studies (e.g. Brönnimann et al., 2019 and references therein). For instance, quantitative approaches to climate risk management, such as mapping or impact modelling, rely on past meteorological data with daily or sub-daily resolution (Brönnimann et al., 2018b). Nevertheless, a large fraction of such data has not been available for scientific analysis. Thus, many initiatives and projects on international (e.g. the Mediterranean climate data rescue (MEDARE, 2007), the Historical instrumental climatological surface time series of the Greater Alpine Region (HISTALP, Auer et al., 2007), the Atmospheric Circulation Reconstructions over the Earth (ACRE, Allan et al., 2011), the European meteorological services network - Data rescue (EuMetNet-DARE, 2018), the International data rescue (I-DARE, 2019)) and national (e.g. NOAA, 2019) levels have been launched in order to digitize these historical records of instrumental meteorological observations (Brunet and Jones, 2011; Brönnimann et al., 2018b; Brönnimann et al., 2019). In February 2020, Copernicus Climate Change Service (C3S) launched a new Data Rescue Portal which aims to make historical observations available via the Climate Data Store. Ultimately, C3S's goal is to combine assets from archives all around the world to make one comprehensive dataset that anyone can use, containing every single observation that has ever been found anywhere (https:// climate.copernicus.eu/new-portal-allows-sharing-historical-weather-observations-climate-research). Such activity by historical climatologists has resulted in many datasets of meteorological records being rescued/digitized from all over the world. For instance, the databases of historical observations of different meteorological variables have been created for countries and regions such as Italy (Camuffo and Bertolin, 2012; Camuffo et al., 2013; Camuffo et al., 2017; Camuffo et al., 2020), Switzerland (Pfister et al., 2019), Portugal (Alcoforado et al., 2012), Spain (Domínguez-Castro et al., 2014; Rodrigo, 2020), UK (Hawkins et al., 2019; Craig and Hawkins, 2020), Mediterranean North Africa and the Middle East area (Brunet et al., 2014; Ashcroft et al., 2018), Canada (Slonosky, 2014) and Australia (Ashcroft et al., 2014). The most comprehensive global inventory of pre-1850 data rescue activities has been published recently by Brönnimann et al. (2019).

Some parts of the Ukrainian historical (up to the end of 19th century) climatological data have recently been made available for scientific analysis as a result of several initiatives (for instance, Osadchyi et al., 2013; Osadchyi et al., 2018; Skrynyk et al., 2019; Boichuk et al., 2019). However, these studies have mainly focused on monthly mean, minimum and maximum values of air temperature. To the best of our knowledge, original meteorological observations conducted in Ukraine in the pre-industrial period have not been used in any analysis. The main objective of this paper is to present results of data rescue activity conducted recently by the Ukrainian Hydrometeorological Institute (UHMI, Kyiv, Ukraine), in close collaboration with the Justus Liebig University Giessen 
(Giessen, Germany), the World Meteorological Organization (WMO) and the Met Office Hadley Centre (Exeter, United Kingdom). Our focus was concentrated mainly on original sub-daily pre-1850 meteorological observations made at eight meteorological/climatological stations located on the territory of modern Ukraine. These eight meteorological stations are the only ones with pre-1850 data that have been found in a specialized archive of the observation institution of the Ukrainian Weather Service the Central Geophysical Observatory (CGO).

\section{2 | MATERIALS/DATA AND METHODS}

The recovered and processed data are from following eight meteorological stations: Kyiv, Kharkiv, Poltava, KamyanetsPodilsky, Lugansk, Dnipro, Kherson and Odesa. The stations are named after the cities/towns of their location. All these stations or, more precisely, stations with the same names are currently operating, and they belong to a modern regular network of the national meteorological monitoring system. Their geographical coordinates and altitudes are presented in Table 1 and in Figure 1 can be seen their distribution in the territory of Ukraine.

\section{1 | Original paper data medium (tables, books and handbooks) with records of weather observations}

The data from all stations were stored on paper (hard copy) format in special tables/books/handbooks where meteorological records were recorded by hand (manually). However, not all of them seem to be 'original' tables (written directly by observers). In several cases, it looks like the records were rewritten (manually copied) into the tables at a later date, but it is not clear when exactly. There is no information about the current location of the 'original' records (probably, they were lost). Information about the numbers of tables/books/ handbooks with data that were found for every station is seen in Table 1. Their total number is 38 . In Figure 2 can be seen an example of the books/handbooks. The quality of the records in the paper sources can be considered acceptable: in the majority of cases, written numbers are clearly visible and can be digitized without problems. Many tables/ books have some text information for providing explanations about their contents. This information in the different books is written in different languages (old Russian, German or French). There is also no unique format of the data records in the tables. They differ from each other with regard to the number of observed/measured meteorological variables, time of observations, and their frequency during a day etc. Examples of the paper tables with the observations are presented in Figure 3.

According to the station histories, published in KHMO (1968), the earliest meteorological observations in Ukraine were conducted mainly at universities or other educational institutions/organizations (e.g. the nautical school in Kherson). These observations were usually organized and conducted by volunteers (by professors or students).

Worth mentioning are several historical events, which, probably, had some influence on both the state of the climatological archive of the Ukrainian Weather Service and the volume of information preserved. The most significant of these is two World Wars and associated events. For instance, during World War II Kyiv, where the archive has been located, was occupied. According to URHMI (1970), the main part of the archive was evacuated from Kyiv before the occupation and it was returned later after the end of the war. As reported in URHMI (1970), some parts of the hard copy books, documents etc. were lost during these relocations. Around 1960, the archive was relocated one more time to a new building and part of the original historical records may

TA BLE 1 Details on the rescued Ukrainian meteorological stations

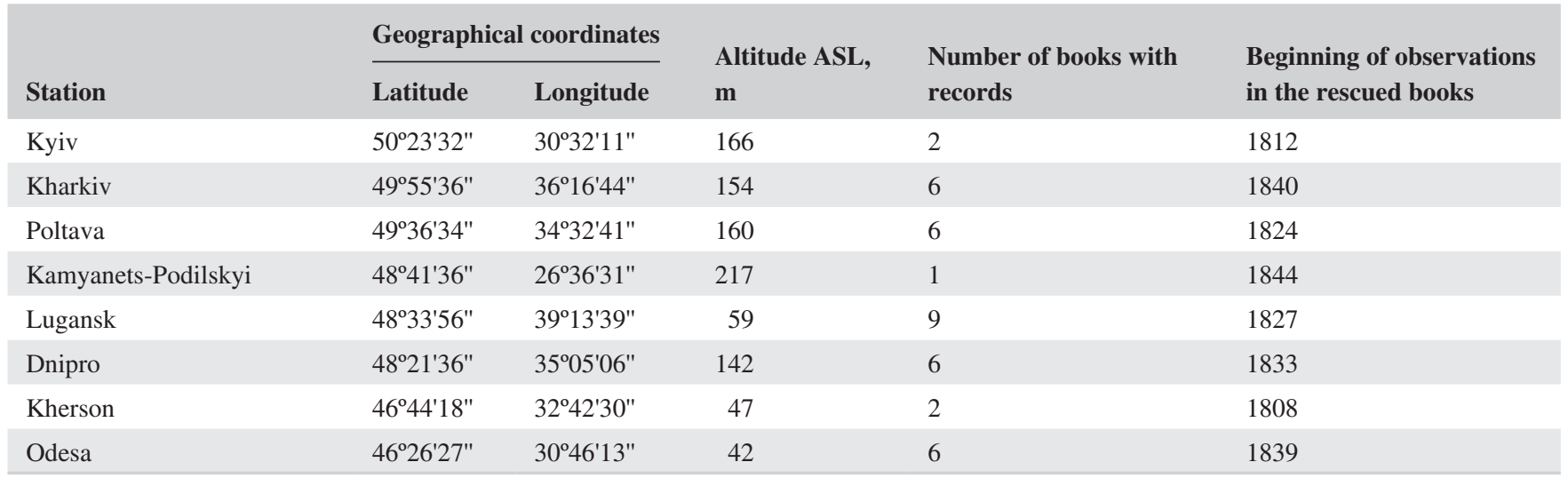

Note: The geographical coordinates and altitudes are given for modern meteorological stations. These metadata are slightly different for the rescued stations because all of them were relocated to new places in every town/city. 

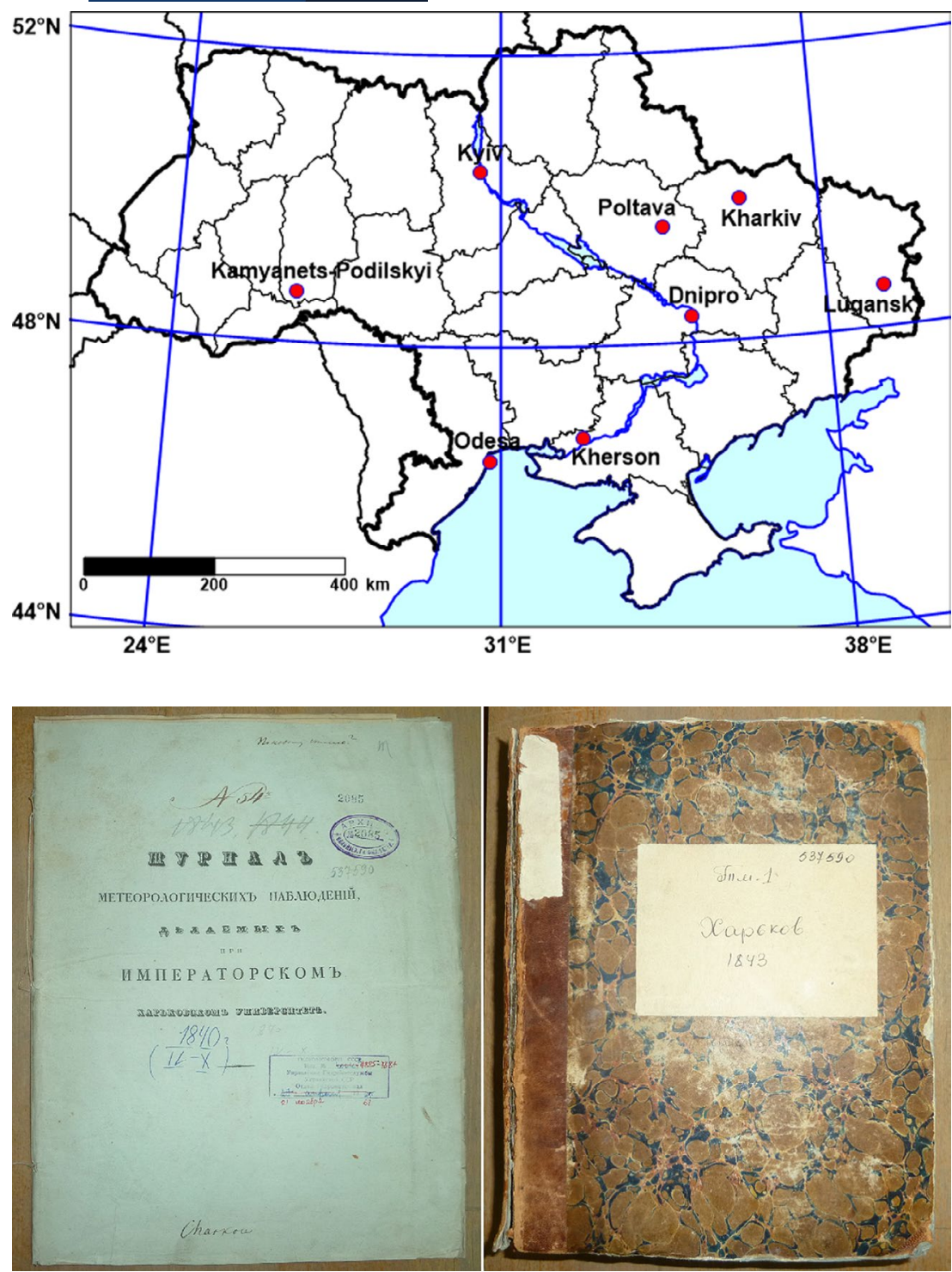

FIGURE 1 Location of the rescued stations on the territory of Ukraine
F IG URE 2 Examples of hardcopy books with meteorological observations from Ukraine. To the left is Kharkiv (Kharkiv, University), 1840; to the right is Kharkiv (Kharkiv, University), 1843 have been lost during this relocation as well. The influence of all these events/episodes on the archive should be studied in more details in the future in order to assess the impact on the quantity and quality of the remaining records.

\section{2 | Data rescue/digitization}

Because the records are handwritten, there is no possibility to automate the digitization process. According to the recommendations of the World Meteorological Organization (WMO, 2016), Wilkinson et al. (2019) and Brunet et al. (2020), in order to facilitate the digitization and further application and usage of these newly found books and data, all pages of the tables/books were photographed firstly. This allowed us to create a database of images of all the paper sources found. Two versions of the database are now stored in UHMI and CGO (Ukraine). During this rescue process, we tried to maintain a balance (by choosing an appropriate resolution of photographs) between the quality of the images and the size of memory required to store each photograph. After the creation of the database of the images, data were digitized manually by the authors during the 7-month period September 2018 to March 2019. In the course of the digitizing process, we followed recommendations outlined by the WMO (2016) with the main rule of 'key as you see' (Ashcroft et al., 2018; Wilkinson et al., 2019; Brunet et al., 2020). However, the suggested double-keying method (Brönnimann et al., 2006) was not applied due to limited financial resources. We digitized values of three variables: air temperature, atmospheric pressure (station level) and amount of precipitation. Other information (mainly short text descriptions of the state of the atmosphere, wind direction etc.) has not been processed. Missing values were marked as ' -999.9 '. The digitized values were stored in Excel tables. In total, eight ( +1 for Kharkiv, University, see below explanations in section 3.1.2) Excel files were created (one file for every station) where data (temperature, pressure and precipitation) were stored/organized by years (that is, data for particular years stored on separate sheets). Years with no 

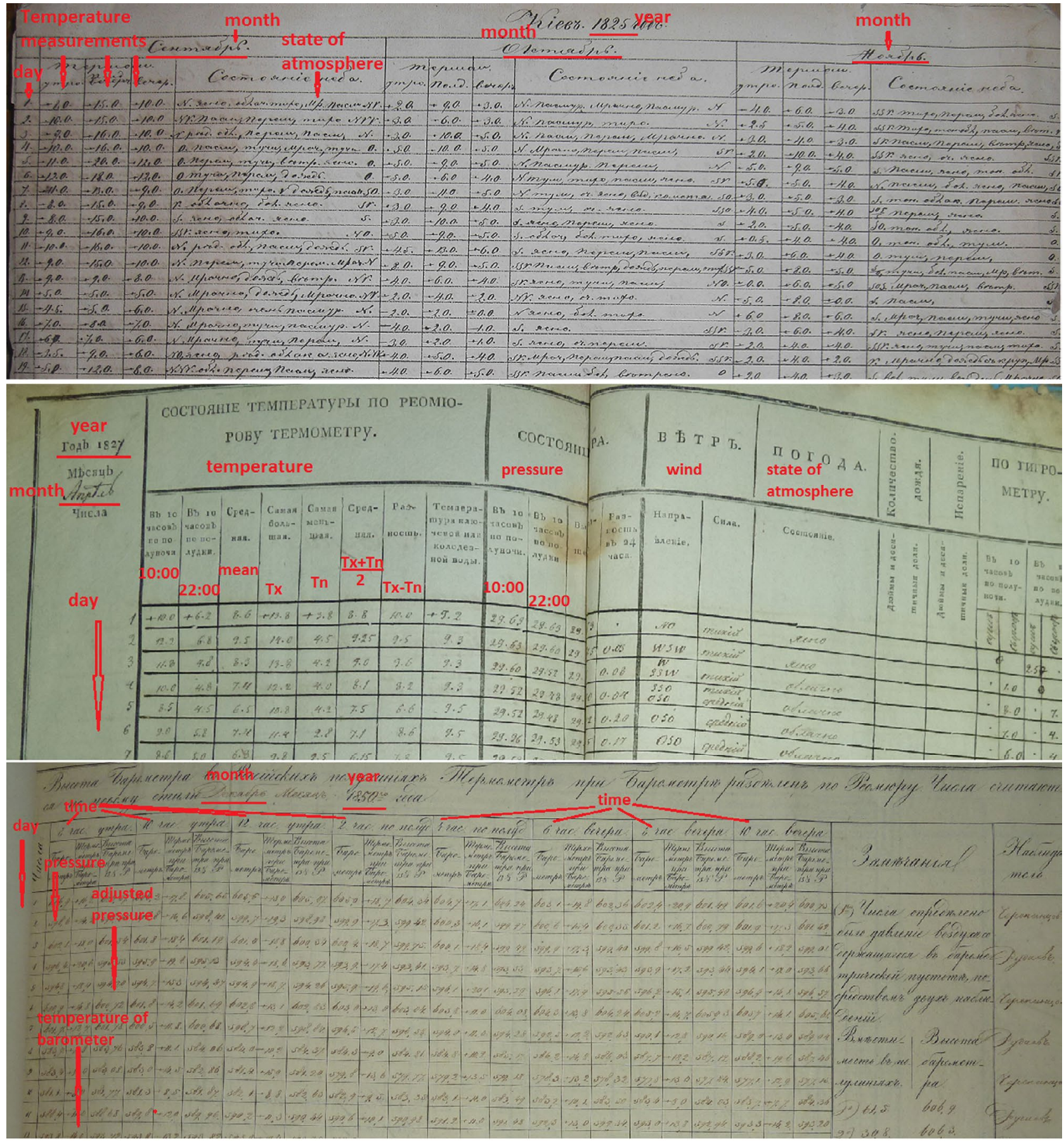

F I G URE 3 Examples of the original paper tables with meteorological observations (some explanations on the photographs are shown in red). Top panel: Kyiv, 1825; middle panel: Kherson 1827; bottom panel: Lugansk 1850

data were not included in the files. An example of the Excel tables with digitized data is presented in Figure 4.

\subsection{The quality control of the rescued data}

Several quality assurance (QA) procedures were performed in order to check the quality of the digitization process and reliability of the rescued data. First of all, the simplest check on very large (positive and negative) and not numeric values was carried out by means of Excel instruments/tools by using appropriate filters. This allowed us to locate and correct very crude digitization mistakes and errors. In addition, we conducted two kinds of comparison of the rescued data on the monthly time scale. Firstly, we compared monthly air temperature data, calculated from the rescued records and monthly averages digitized previously by Osadchyi et al. (2018) from another paper source (URHMI, 1953). This 


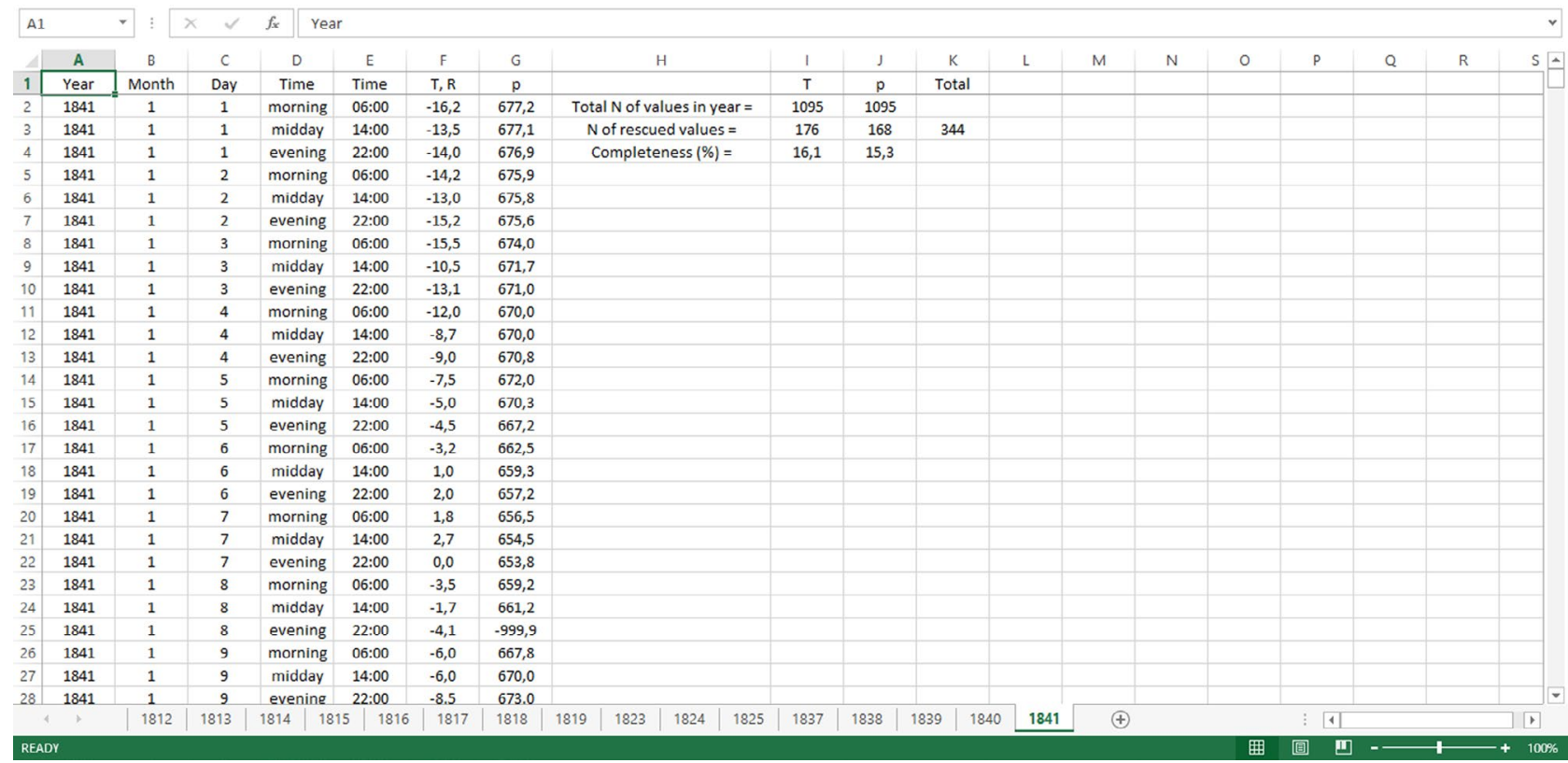

F I G U R E 4 Example of the Excel tables with digitized data (for the station Kyiv, January 1841)

source is a special handbook containing Ukrainian historical (pre-1950) monthly air temperature data. Unfortunately, Ukrainian monthly atmospheric pressure data for the same period were not published in special issues or at least, we were not able to find them. Therefore, it was only possible to perform this comparison for air temperature. The second QA procedure conducted on the monthly scale data was a mutual comparison of rescued stations by means of the HOMER software (Mestre et al., 2013). HOMER is a homogenization software designed to remove artificial artefacts (abrupt breaks, gradual trends, outliers, etc.) from climatological time series with monthly time resolution. However, it also contains a QA module, which allows one to perform quality control of data based on a mutual comparison of stations (Mestre and Aguilar, 2011).

\section{3 | RESULTS AND DISCUSSION}

The amounts of rescued data for every station and every year are summarized in Table 2. In total, we rescued 291,103 values. This includes 165,980 rescued air temperature records ( $\sim 57 \%$ of the total), 124,376 atmospheric pressure measurements ( $42.7 \%$ of the total) and 747 precipitation values ( $\sim 0.3 \%$ of the total). Due to a small number of precipitation data, they were not processed further. Tables 3 and 4 display the completeness of temperature and pressure time series for each year starting since 1808, which is the earliest year with available records. The percentages were calculated based on a supposed number of measurements per year defined using the number of observations per day. Precipitation data were not clearly indicated in the original books as numbers but mainly as text description. Only books/tables from Kharkiv station include atmospheric precipitation data in a numeric form and the 747 rescued precipitation records belong to this station. As can be seen in Table 2, there is the 3-year gap (1820-1822) with no records at all. No records of air temperature were found for 1820-1822, whereas atmospheric pressure data were completely missing for 1816, 1819-1822 and 1828. More detailed information on the rescued data for each station is presented below.

\section{1 | Details of the DARE activity for the stations}

\subsection{1 | Kyiv}

According to a historical description of meteorological observations at Kyiv (KHMO, 1968), the earliest measurements in the capital of Ukraine date back to 1,770. However, we were able to find sub-daily data only from February 1812 until February 1841. Moreover, two periods (1820-1822 and 1826-1836) are missing. During the whole period, observations were conducted three times per day, though the exact time of the day is reported only since 1837. In earlier records, only the fraction of the day (morning, midday and evening) was specified. During the period of 1812-1825, only temperature records were reported (in Reaumur degree). These three temperature measurements for every day were also accompanied by very short information regarding the general state of the atmosphere (such as 'clear' and 'cloudy') and written information regarding wind direction. The directions were marked by capital letters ' $\mathrm{N}$ ' (North), 'S' (South), 'O' 
TABLE 2 Number of rescued values

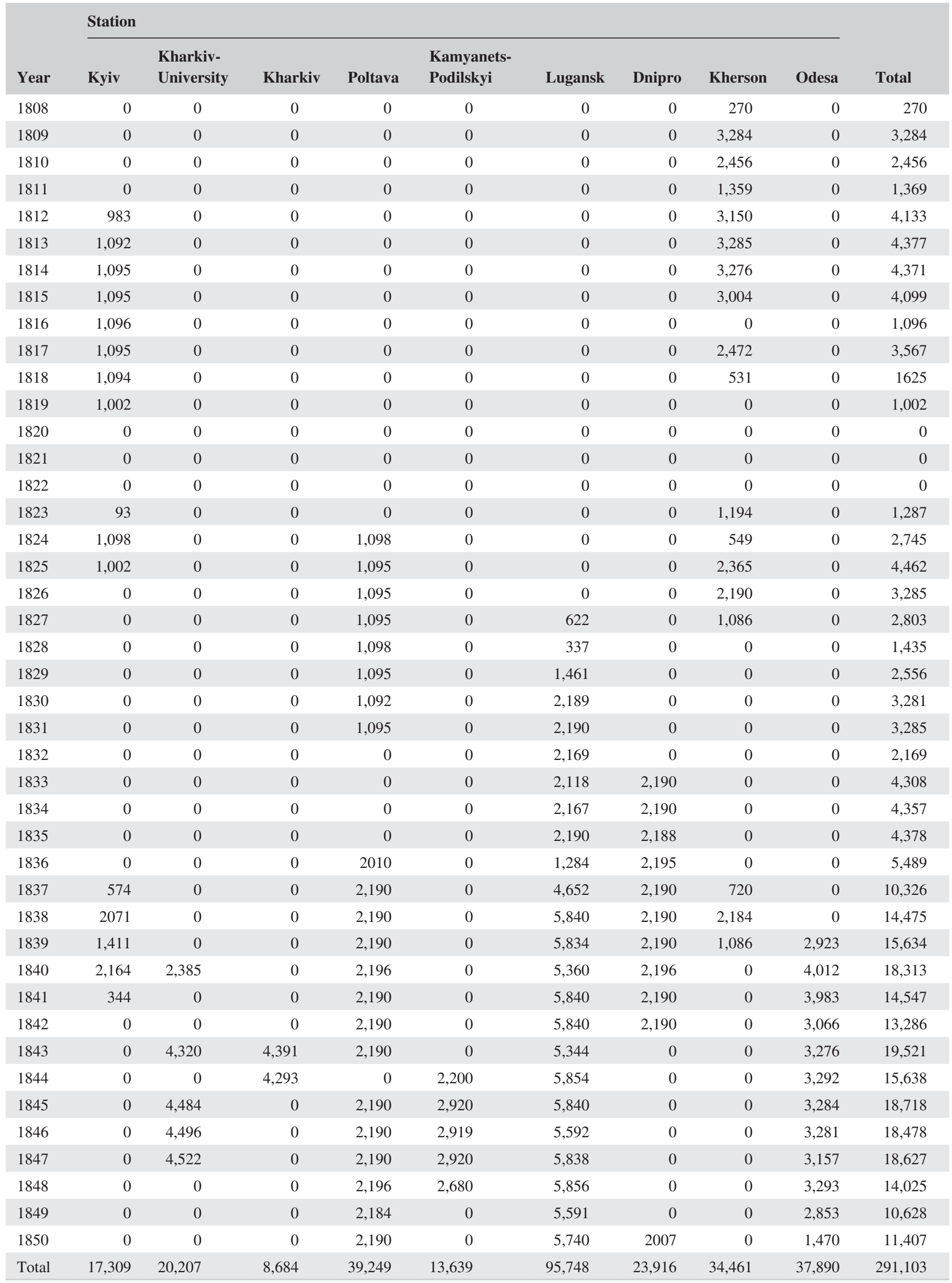


TA B L E 3 Completeness of the rescued air temperature time series for every year (in \%)

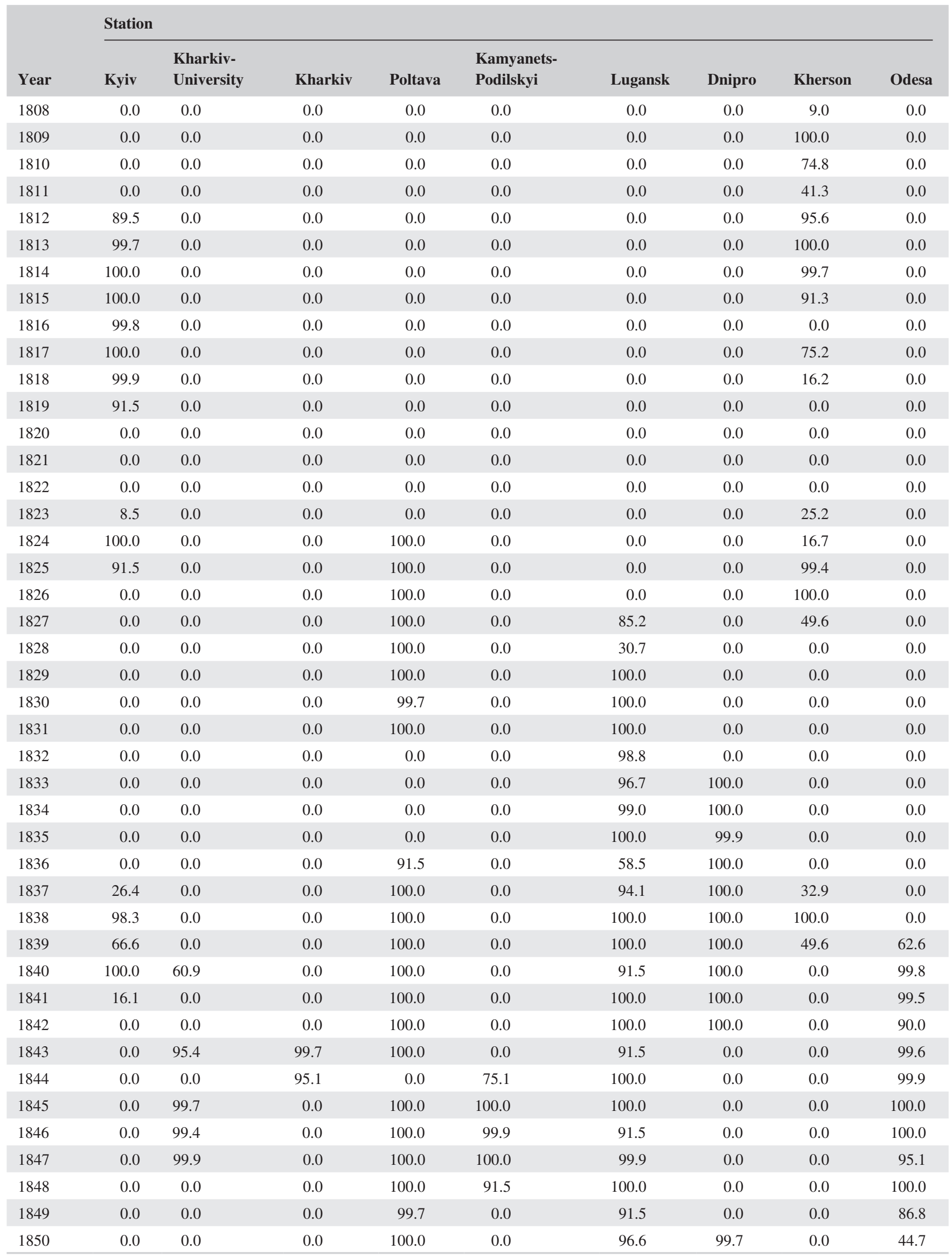


T A B L E 4 Completeness of the rescued air pressure time series for every year (in \%)

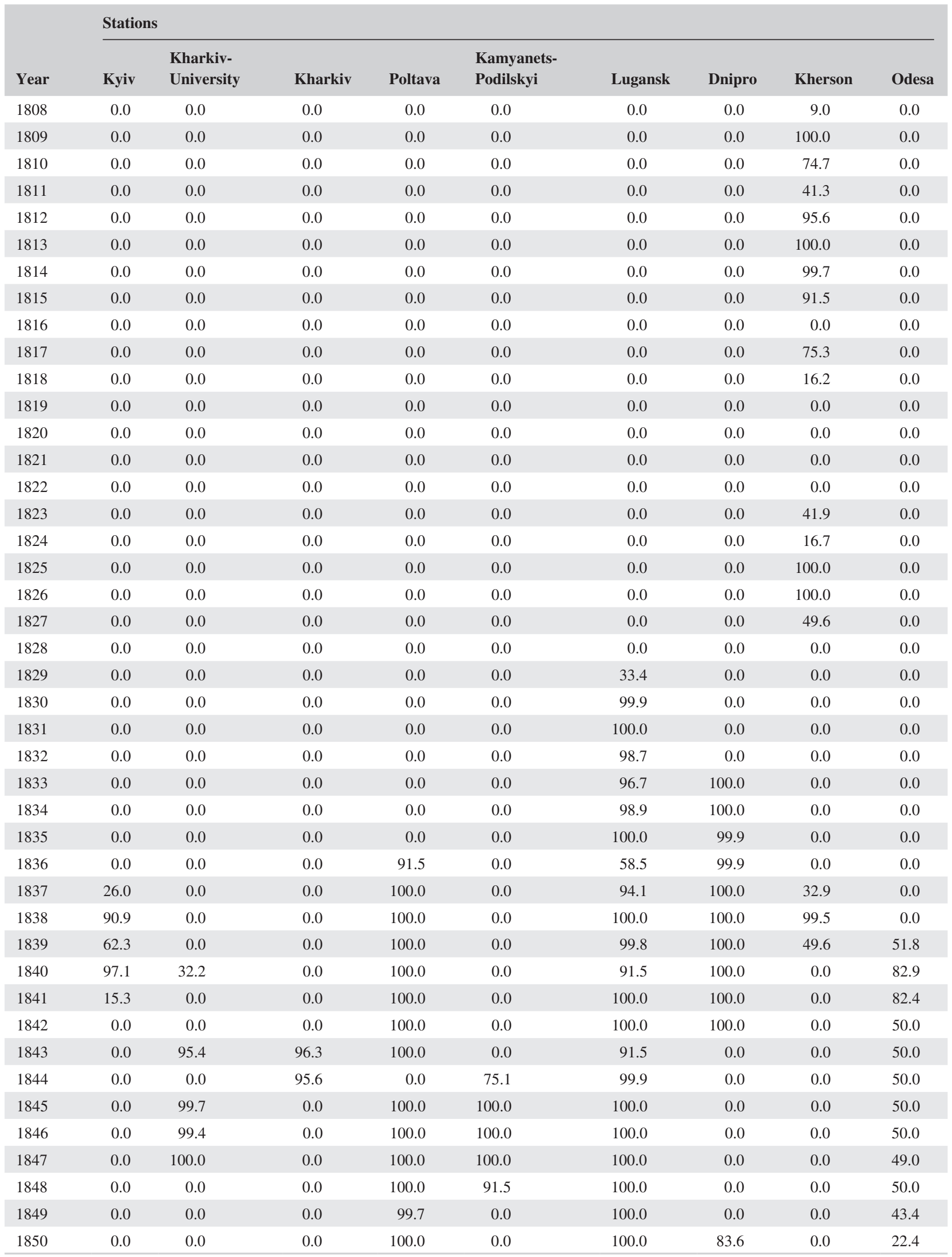


(East from German 'Ost'), 'W' (West) or their combinations such as 'SO' (Southeast) etc. Since 26 September 1837 data were recorded in new tables (book/format): starting from this date, atmospheric pressure was also reported. The supporting text (some explanations) and some observations (including a state of the atmosphere) were given in German. The units for atmospheric pressure records were not reported clearly. However, based on the comparison of the rescued values with similar data from other stations (Poltava, Lugansk and Dnipro), we can assume that this variable was measured in Russian semi lines (R.s.l.). According to (Shostin, 1975; Lamb, 1986) this unit can be converted into millimetres based on the relation 1 R.s.1. $=1.27 \mathrm{~mm}$. That is, $1,000 \mathrm{hPa}$ $=1,000 \mathrm{mbar}=750.06 \mathrm{mmHg}=590.60$ R.s. 1 .

An example of the rescued time series collected at Kyiv is shown in Figure 5. Here, air temperature in 1816, known as 'the year without summer' (Brugnara et al., 2015; Luterbacher and Pfister, 2015; Raible et al., 2016), is presented for three periods during each day. Though the exact time of the measurements was not specified in the original hard copy tables, we assume that the measurements were conducted at 06:00, 14:00 and 22:00 (local time), as was pointed out in the paper sources for later periods. The modern climate sub-daily data with measurement times closest to the supposed observations in 1816 are also shown in the figure for comparison. We depicted time series for each year of the 1981-2010 period as well as mean data averaged over 1981-2010. As can be seen from the figure, 1816 conditions are comparable with the present climate and probably the climate conditions in Ukraine in 1816 were not impacted significantly by the Tambora eruption in contrast to other parts of Europe (Luterbacher et al., 2004; Xoplaki et al., 2005; Luterbacher and Pfister, 2015; Brugnara et al., 2015). It will be interesting to compare these time series with similar air temperature data for other places in Europe for the post-Tambora period (Brugnara et al., 2015).

\subsection{2 | Kharkiv (Kharkiv, University)}

The earliest meteorological observations in Ukraine were, probably, organized in Kharkiv in 1738 (KHMO, 1968). However, only several years of observations prior to 1850 were discovered in the archive: 1840 and 1843-1847. Two stations, namely Kharkiv and Kharkiv, University, seemed to be operating in the pre- 1850 period in this city. Such a conclusion can be made based on the hard copy books with
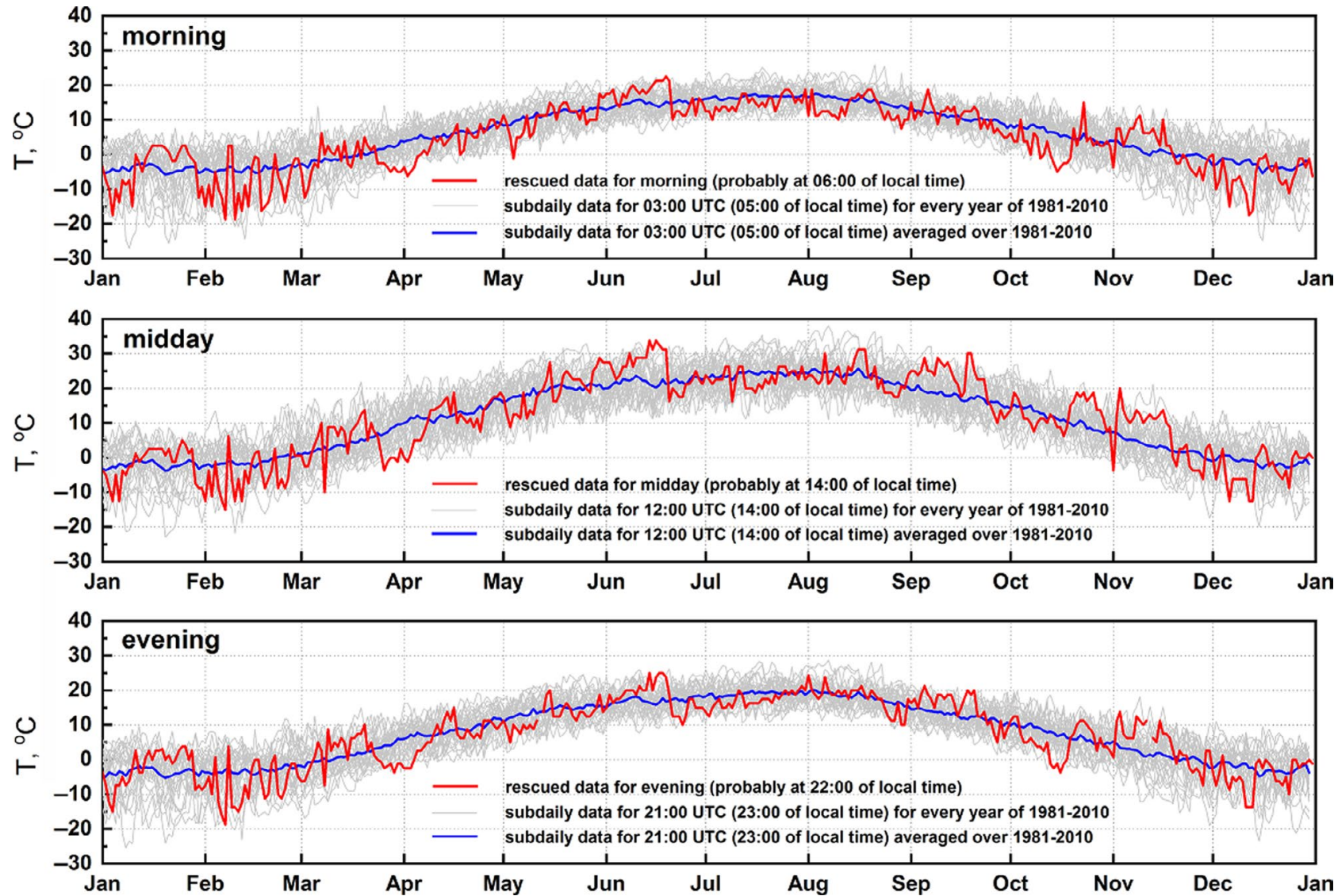

F I G U RE 5 Time series of sub-daily air temperature measurements at Kyiv in 1816. Temperature data were converted to the Celsius scale based on the relation $1{ }^{\circ} \mathrm{C}=1{ }^{\circ} \mathrm{R} * 5 / 4$. The present climate sub-daily data (1981-2010) measured at the times closest to the supposed historical observations are also shown for comparison 
meteorological records: we found two different books with data of 1843 (books with different structures of records, which were, probably, written by different persons, judging by the handwriting styles). However, only temperature data are different for the first months of 1843 while all the values of air pressure and air temperature for the remaining months are almost the same. This fact was discovered after the rescuing as similarities between the data were not recognized during the digitization process. All data of all books were rescued and included in the digitized database (see Tables 2-4) but in our description and analysis, the stations are mainly interpreted/ treated as the same station. The number of meteorological observations per day varied over time. Nine measurements a day with a two-hour interval starting at 6 a.m. and ending at 10 p.m. of the local time were reported in April-August of 1840 , while only three records a day were written in the book in September-October of 1840. The rest of the available period is specified with six measurements a day. Air temperature during the whole period was measured in the Reaumur scale. Atmospheric pressure was reported in R.s.l., while precipitation was recorded in inches. Similar to other stations, supporting verbal information was provided along with meteorological data. Moreover, one hard copy book contained other numeric information (like daily maximum and minimum air temperature). Nevertheless, due to the fairly short period of such additional measurements, they were not digitized.

\subsection{3 | Poltava}

Meteorological observations in Poltava started in 1824 (KHMO, 1968) and are recorded in the recovered hard copy tables. Poltava seems to be one of the stations where the discovered paper sources contain records of meteorological observations from the very beginning of the station's operation. Despite two missing periods (1832-1835 and 1844), the time series of this station for separate years are amongst the most complete with minimal numbers of missing values (see Tables 3 and 4). During the years available, meteorological observations were conducted three times a day, however, the exact time of measurements is indicated only since 1838 . Before this year, the time of the measurements was specified just as a period of the day (morning, midday, evening) similar to other stations. Air temperature was recorded in the Reaumur degree during the whole period. Atmospheric pressure records are available only since 1836. Firstly, this variable was measured in inches. However, from 1847 onward R.s.l. were indicated as measurement units. The hardcopy books also contain some additional information, but not in numeric form, mainly as a short description of a state of the atmosphere and wind information. Nevertheless, from 1847 some numeric information regarding water vapour was also specified in the books, this info was not processed.

\subsection{4 | Kamyanets-Podilskyi}

This is the station with the lowest number of rescued values and years. Just one hard copy book with data records covering the period of 1844-1848 was found in the archive. The year 1844 is also mentioned as the beginning of the station (KHMO, 1968). Only two years, 1849 and 1850, are missing from the pre-1850 time frame. The meteorological measurements at Kamyanets-Podilskyi were performed four times a day: at 08:00, 12:00, 16:00 and 20:00 (local time). Similarly to other stations, air temperature was measured based on the Reaumur scale. Atmospheric pressure was recorded in inches. The values of these two meteorological variables were the only numeric meteorological information recorded in the handbook. Short verbal information regarding the wind and a state of the atmosphere is also provided.

\subsection{5 | Lugansk}

The largest amount of values of meteorological variables, covering the longest period of consecutive years, was recovered for this station (see Table 2). According to the rescued paper sources, original records of meteorological observations were found for 1827-1850 (continuous). Year 1827 is also acknowledged (KHMO, 1968) as the beginning of meteorological observations in Lugansk. The number of the meteorological observations per day at this station changed several times. During the first year 1827, not more than two measurements were taken each day, usually in the morning and at midday, or only at midday. In the period of 1828March 1837, three measurements were performed, while in the period of April 1837-1850 it was specified that eight measurements a day were made. Air temperature was measured based on the Reaumur scale during the whole period. Atmospheric pressure has been recorded since 1829, and values were given in inches during the period of 1829-1838. However, during nine months in 1837, as well as other years starting from 1839, pressure was recorded in R.s.l.. Similarly to other stations, short textual information on wind and a state of the atmosphere was also provided in the hard copy books. It is also worth noting that Lugansk is the only station where its relocation in 1843 was clearly specified (KHMO, 1968).

\subsection{6 | Dnipro}

According to the published description of the station history (KHMO, 1968), meteorological observations in Dnipro started in 1833 . The rescued paper sources also contain meteorological records since that year; however, the period of 1843-1849 is missing. During the whole period, the measurements were performed at specified times three times per day. Air 
temperature was recorded in Reaumur degrees. Atmospheric pressure was firstly (1833-1838) recorded in inches, but later (1839-1842, 1850) R.s.l. were used as units for this variable. Additional textual information (like a short description of wind direction) was also included in the hardcopy books.

\subsection{7 $\quad$ Kherson}

The hardcopy books for this station contain the oldest records of meteorological observations conducted in Ukraine. The data cover the period of 1808-1839. However, there are several substantial missing periods (1816, 1819-1822 and 18281836). It also should be mentioned that according to KHMO (1968), meteorological observations in Kherson started in 1801 , but we could not find these records for the period 18011807 in the archive. The number of measurements per day varied during available years. In the period 1808-February 1825, three measurements (with the time specified as 'morning', 'midday' and 'evening') were performed, while in the period of March 1825-1827 only two measurements were conducted (at 10 a.m. and 10 p.m. of local time). The rest of the available years (1837-1839) was again specified with three measurements per day. Atmospheric pressure was recorded since 1808 using inches as units. Two values of air temperature during 1808-February 1825 were recorded every time of measurement, and both of them were digitized. These two values of temperature were marked in the paper source as 'on S' and 'on N', probably meaning 'on South' and 'on North' walls. The differences between these two temperatures are very small. Such temperature time series seem to be something like 'parallel' measurements. However, no detailed information was found regarding these slightly different temperature values. During the period of March 1825-1827, along with two values of temperature, measured at 10 a.m. and 10 p.m., values of minimum and maximum air temperature were also provided in the hardcopy book. They were also digitized. Finally, during 1837-1839 three values at regular measurement times (again specified as 'morning', 'midday' and 'evening') were recorded in the book. All temperature values (during all mentioned periods) were measured according to the Reaumur scale. Some additional information was also provided in the rescued books; however, it was mainly short verbal description of the state of the atmosphere.

\subsection{8 | Odesa}

According to KHMO (1968), meteorological observations in Odesa started in 1821. However, the hardcopy books contain data records only since 1839 with no missing years until 1850. Supporting information in the books is written in French. The records of the observations at this station are characterized by the high variability of a number of measurements per day. Moreover, the numbers of air temperature and atmospheric pressure measurements and their times are different in many cases. For instance, during April of 1839 four records of both meteorological variables can be found in the book, while in May 1839 five measurements for pressure and seven for temperature were reported. Air temperature was measured using the Reaumur scale; atmospheric pressure is presented in inches. However, there are additional values in the books, which represent the same atmospheric pressure in R.s.l.. Such 'parallel' data can be used for defining the conversion formula. It is also interesting to note, that the data for 1842-1850 do not have a strict table structure but are organized as simple text lines of numeric and character information.

\section{2 | Results of QA procedures}

\subsection{1 | Comparison of rescued data with previously digitized values (on monthly time scale)}

Monthly mean data of air temperature for Ukrainian stations until 1950 were published in the special issue in 1953 (URHMI, 1953). The content of this handbook was prepared by climatologists of the Ukrainian Research Hydrometeorological Institute (the former name of UHMI) and was published by the National Academy of Sciences of the former Ukrainian Soviet Republic under supervision of one of the government Ministries. The handbook is an official edition that reflects the current (based on 1950) state of Ukrainian monthly air temperature data (their availability in archives, their checking by QA procedures existing at that time, etc.). Therefore, the handbook can be considered as a reliable source of climatological information. However, the introductory part of URHMI (1953) contains very short and fairly general metadata information regarding sources of meteorological observations/measurements (where monthly data were calculated from), their quality, calculating algorithm, etc. Therefore, there is no possibility to check the correctness of the data based on original paper sources and we should acknowledge that errata, mistakes and wrong data might be present in the datasets. Nevertheless, we believe that these data can be used in order to verify the rescued records and to get an idea about their quality.

We note, that according to the preface of URHMI (1953), the monthly temperature data were published in this handbook with corrections in order to adjust daily averages, calculated based on a limited number of sub-daily records, to 'true' daily values. The magnitudes of correction factors were reported in URHMI (1953) for every station, month and year 


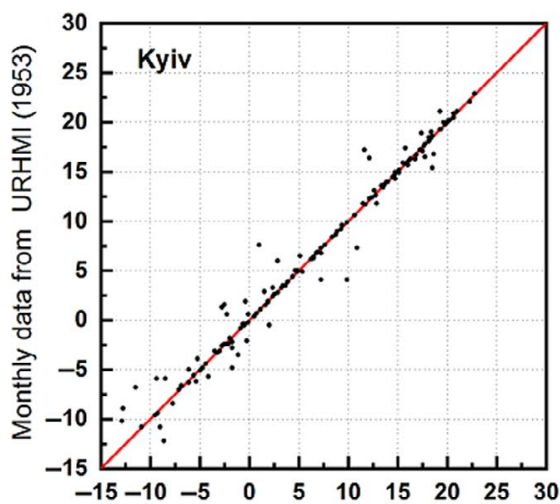

Monthly data from rescued values

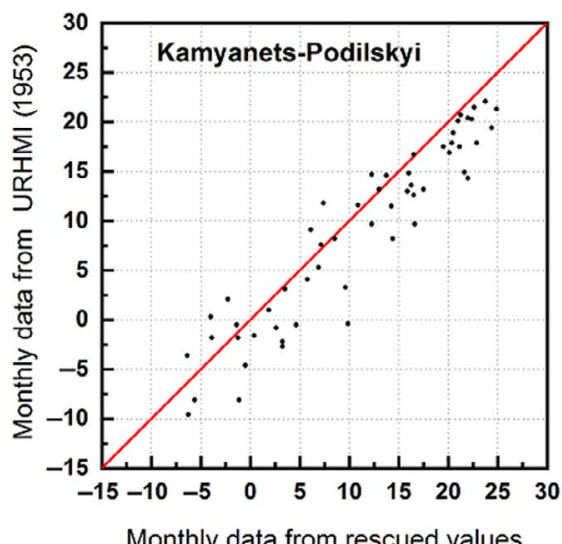

Monthly data from rescued values

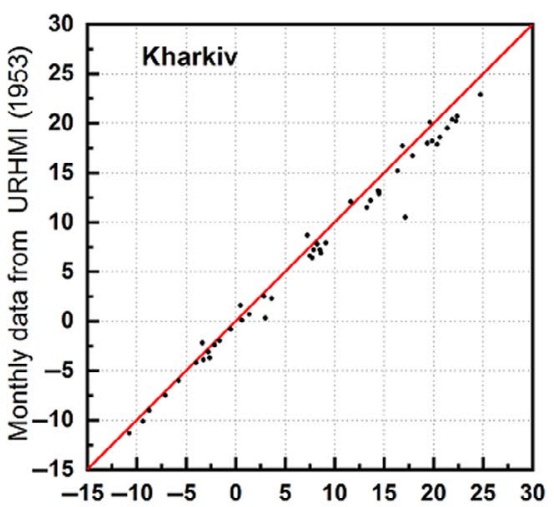

Monthly data from rescued values

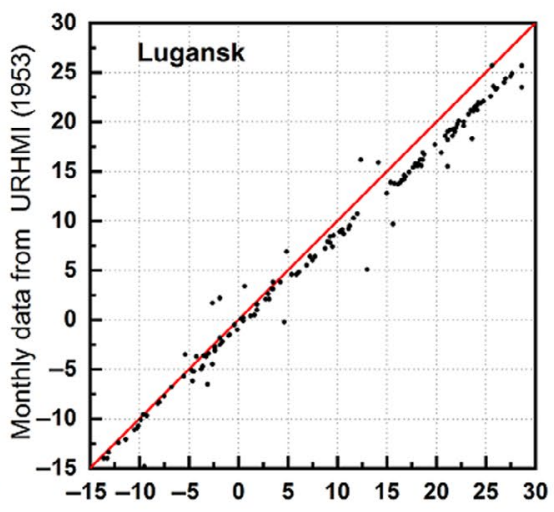

Monthly data from rescued values
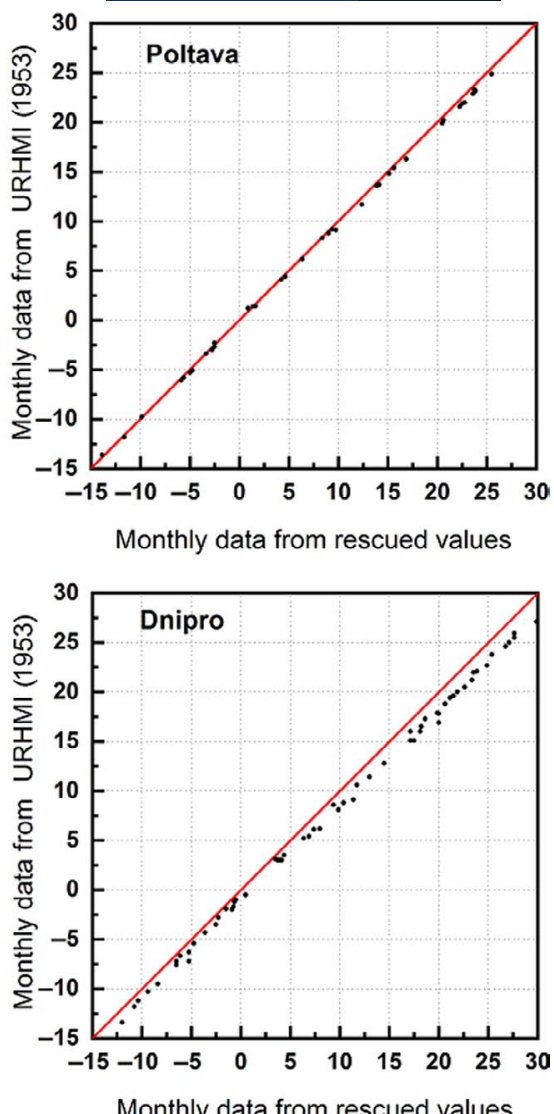
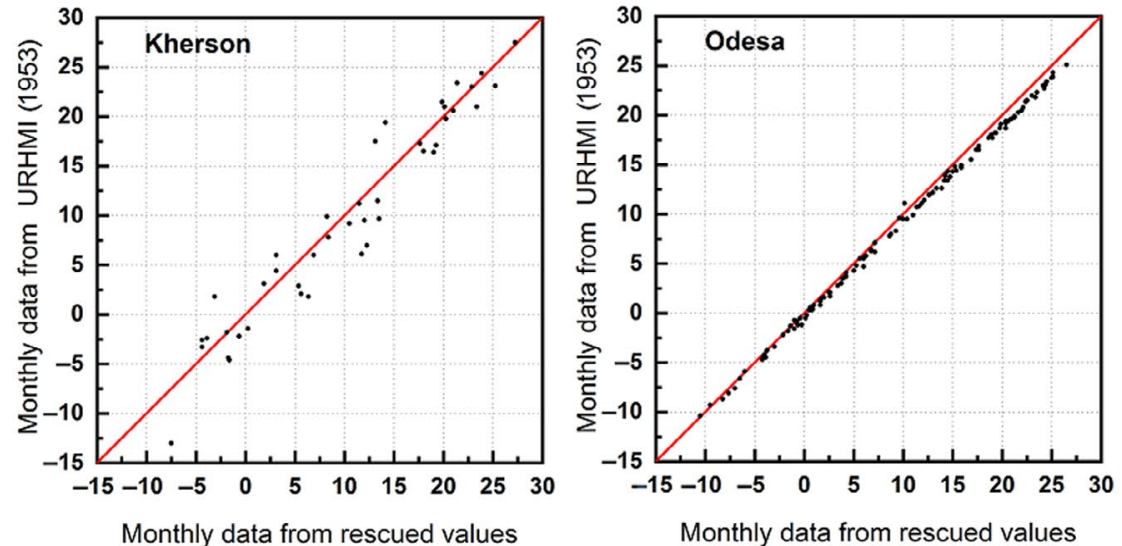

F I G URE 6 Scatter diagrams showing the relationships between monthly air temperature data digitized from URHMI (1953) and monthly temperature values calculated from the rescued data

along with the corrected data. However, there is no information regarding the methodology that was used to calculate the corrections. In our comparison study, we used uncorrected 'original' data: the correction factors were subtracted from the time series. The monthly data from the rescued material were calculated in several steps. Firstly, we calculated daily averages based on sub-daily records. In order to increase the reliability of the comparison, we computed daily values only for those days when no missing sub-daily measurements were reported. Then, the monthly data were calculated based on the WMO ' 3 and 5' rule (WMO, 1989). Finally, the monthly averages were adjusted/transformed to the Celsius scale based on the relation $1{ }^{\circ} \mathrm{C}=1{ }^{\circ} \mathrm{R} * 5 / 4$, because data in URHMI (1953) were reported in degrees Celsius.

The scatter diagrams, where monthly data URHMI (1953) are depicted against similar values calculated from the rescued dataset, are presented in Figure 6. As can be seen, the rescued data from Poltava station are in very good agreement with monthly data compiled and published in 1953, while the largest differences are observed at two stations, KamyanetsPodilskyi and Kherson. This probably means that the rescued data for these two stations should be used with caution due to the relatively large discrepancies between the monthly averages and the similar values published in URHMI (1953). 

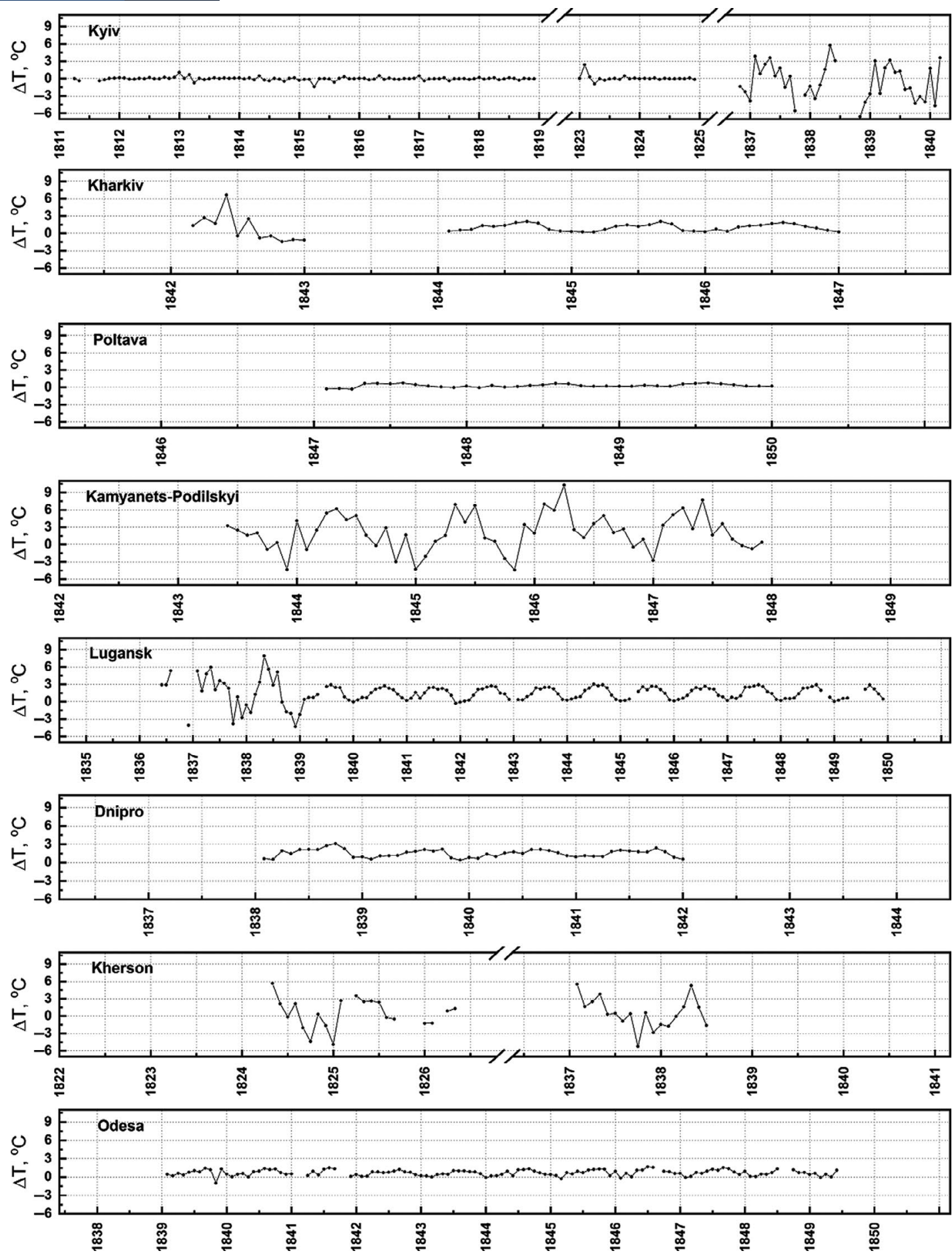

F I G U RE 7 Time series of differences between monthly data calculated from the rescued records and from URHMI (1953)

At the majority of stations (apart from Kyiv, KamyanetsPodilskyi and Kherson), deviations/anomalies between the two kinds of monthly data increase with temperature magnitude (see Figure 6). This leads to the significant seasonal/ periodic course of the anomalies that is shown in Figure 7. Moreover, for all these stations, monthly values calculated from the rescued data are overestimated compared with data from URHMI (1953). Such peculiarities (including the seasonal change) of the calculated deviations are difficult to explain. One of the possible reasons might be a limited and small number of sub-daily measurements per day. For instance, three measurements (say at 07:00, 14:00 and 21:00 as at the Poltava station in 1838-1850) approximate a 'true' daily averaged value in summer in a different way (with different error) compared with winter.

It is also interesting to note that at several stations (Kyiv, Kharkiv and Lugansk) the magnitudes of the deviations are substantially different during different time periods. For 

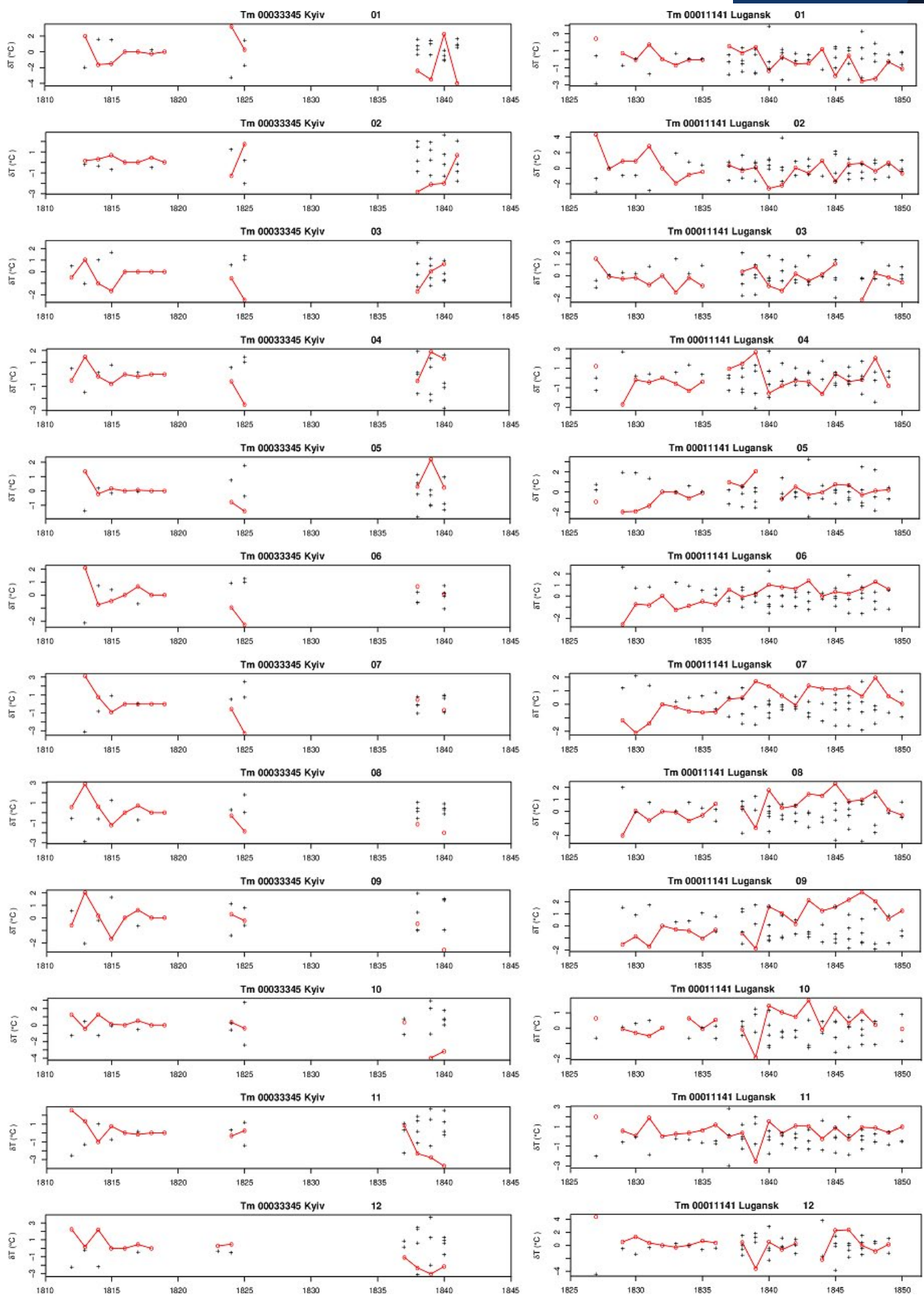

F I G U RE 8 Graphical output of the HOMER QA procedure for air temperature at Kyiv and Lugansk. The plots show time series of air temperature anomalies at a candidate station (red dots linked with red lines) and reference stations (black crosses) for each month (01-12). The anomalies are calculated as the deviations of monthly averages from corresponding spatially mean values

instance, at the station Kyiv the anomalies in 1837-1841 are much larger than in the rest of the years. For the stations, Kharkiv and Lugansk such periods are 1842-1843 and 18361839 , respectively.

Below we provide several additional reasons, which could have some influence on the discrepancies between the two different monthly temperature data. (1) Algorithms for calculating monthly values from sub-daily measurements might be different in the two datasets. (2) Probably, the monthly data in URHMI (1953) for some stations were adjusted/recalculated to the 'New Style' of the calendar (Gregorian calendar), while monthly data calculated from the rescued values were obtained in the 'Old Style' (Julian calendar). We calculated the monthly data according to the 

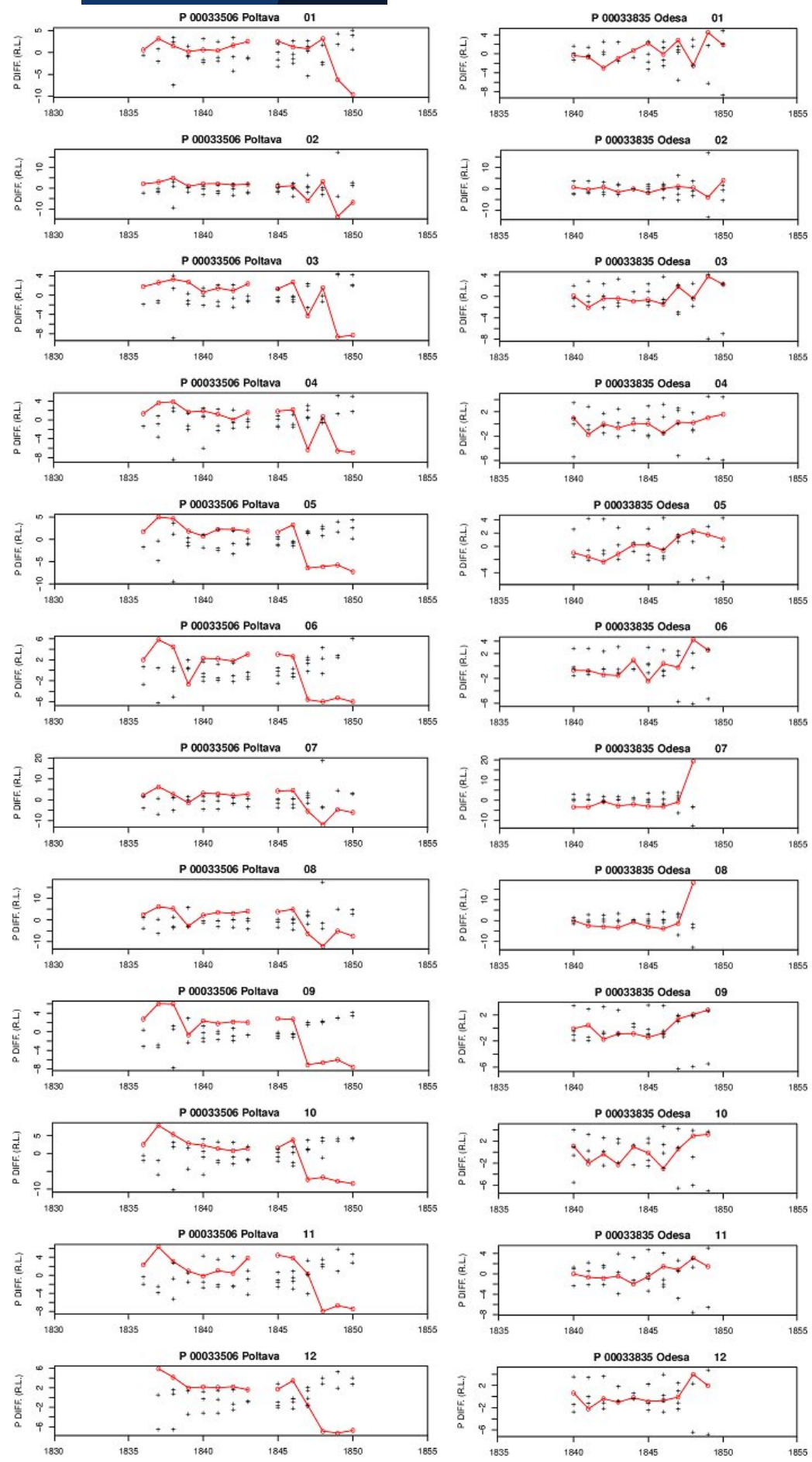

F I G URE 9 Graphical output of the HOMER QA procedure for atmospheric pressure at Poltava and Odesa. The plots show time series of atmospheric pressure anomalies at a candidate station (red dots linked with red lines) and reference stations (black crosses) for each month (01-12). The anomalies are calculated as the deviations of monthly averages from corresponding spatially mean values dates in the original records (without any time shift). The transition from 'Old' to 'New' style (shift on 13 days) in the territory of modern Ukraine was performed only in 1918. However, this does not explain why we have a fairly good accordance between monthly values at several stations and time periods.

In general, we conclude that it is challenging to provide more detailed explanations of the observed discrepancies due to scarce information or metadata provided with the datasets in URHMI (1953).

\subsection{2 | Mutual comparison of rescued stations on the monthly time scale (air temperature)}

The QA part of the HOMER software allows us to perform a mutual evaluation of monthly time series and to localize outliers. As an example, we present the graphical output of the HOMER QA procedure for stations Kyiv and Lugansk (Figure 8). In such figures/outputs, the deviations of monthly averages from spatially local mean values are presented for 
every month and every year. The red dots linked with red lines represent the analysed station and black crosses denote reference ones. In our case, we used in the calculations all the rest of the stations as reference. As can be seen from the figure, the monthly data at station Kyiv for the periods of 1824 1825 and 1837-1841 look like outliers for most months, while the similar data at Lugansk seem to be in more or less satisfactory accordance with measurements at other stations. However, due to the large number of missing values along with the small number of stations analysed (see SM1 with the HOMER diagnostic file for more details) the results of such evaluation do not seem to be so reliable. Nevertheless, the data for all suspicious months on all stations were checked one more time in the hardcopy sources in order to ensure that there were no digitization errors. In general, we can conclude that the mutual evaluation of the rescued air temperature time series on the monthly time scale by means of the HOMER software supports the conclusions drawn with the previous QA procedure.

\subsection{3 | Mutual comparison of rescued time series on monthly time scale (atmospheric pressure)}

Mutual comparison of the rescued atmospheric pressure time series seems to be the only choice to evaluate the quality of the data. Similar to air temperature, we conducted such comparisons on the monthly scale by means of the HOMER software. In order to perform, the evaluation we adjusted/ transformed all pressure data to the same unit (R.s.l.). The problem was that records of atmospheric pressure in the paper sources for different stations and on different periods were reported in different units, which were not clearly specified. In such cases, we defined the units by a comparison with other stations where they were specified.

An example of graphical outputs of the HOMER QA procedure is presented in Figure 9, where just two stations (Poltava and Odesa) are considered. The analysis of all figures suggests that the rescued atmospheric pressure data on almost all stations are comparable between each other. The only exception is the pressure data at Kyiv, which are slightly overestimated in comparison with other stations (see SM2). The reason for such overestimation is not completely clear and should be studied further. Besides, it looks like the time series from several stations have break points. For instance, a shift in $~ 1847$ at Poltava (Figure 8) in almost all months is clearly seen. However, no metadata for this year and station were found in the station history (KHMO, 1968). Similarly to air temperature data, all suspicious values, which looked like outliers, were checked one more time in the original paper sources in order to account for any digitization errors. Generally, we can summarize, that the more detailed evaluation of the quality of the rescued pressure records by means of the HOMER software is difficult to perform due to the large number of missing values and the limited number of stations analysed (see SM2 with the HOMER diagnostic file for more details).

\section{4 | CONCLUSION}

In this contribution, we reported about the DARE activities of the pre-1850 meteorological observations conducted at eight Ukrainian climatological stations. The data rescue was performed at the Ukrainian Hydrometeorological Institute in close collaboration with several international partners. To the best of our knowledge, these original sub-daily data of meteorological observations that were conducted in Ukraine in the pre-1850 period are made available for the first time to scientific analysis. According to the QA procedures performed, the rescued air temperature data from two stations, namely Kamyanets-Podilskyi and Kherson, should be used with caution due to relatively large discrepancies between the monthly data calculated from the rescued records and those published in other paper sources. The same conclusion applies to the rescued data from the station Kyiv for the period of 1837-1841, Kharkiv for 1843 and Lugansk for the period until 1839. The temperature data at the monthly time scale from the other stations and other periods are in good agreement with data from URHMI (1953), which can be considered as an indirect proof of their quality. The HOMER QA procedure generally supports this conclusion.

The comparison of the rescued atmospheric pressure time series by means of the HOMER software (on monthly time scales as well) showed good agreement between the pressure data at different stations. The only exception was the station Kyiv, where the pre-1850 pressure data are slightly overestimated compared with other stations. The presence of possible break points in the pressure time series at several stations was also reported. However, we also acknowledge that the HOMER QA procedure did not provide conclusive information regarding the quality of the rescued records due to the large amount of missing data and the very limited number of the climatological stations considered. Nevertheless, the rescued dataset can be used for different meteorological and climatological purposes including the analysis of extreme events, the contribution to the creation of reanalysis products and can be considered as an important supplement to existing digitized archives of original meteorological measurements performed in the first half of 19 th century.

\section{ACKNOWLEDGMENTS}

This work is part of the Atmospheric Circulation Reconstructions over the Earth (ACRE) initiative. It has been 
partly supported by the Justus Liebig University Giessen, Germany. OS also acknowledges the IDECIS project (the ERA4CS Cofound Grant Agreement no690462) for the support during the final stage of the manuscript preparation. RA is supported by funding from the Joint BEIS/Defra Met Office Hadley Centre Climate Programme (GA01101). RA also acknowledges the University of Southern Queensland, Toowoomba, Australia, and the Centre for Maritime Historical Studies, University of Exeter, Exeter, UK, where he is an Adjunct and Honorary Professor, respectively. The authors are grateful to anonymous reviewers for careful reading of the manuscript and valuable comments and suggestion that improved the quality of the paper.

\section{OPEN PRACTICES}

This article has earned an Open Data badge for making publicly available the digitally-shareable data necessary to reproduce the reported results. The data is available at https:// doi.org/10.15407/uhmi.report.01 Learn more about the Open Practices badges from the Center for OpenScience: https:// osf.io/tvyxz/wiki.

\section{OR CID}

Oleg Skrynyk (iD https://orcid.org/0000-0001-8827-0280

Jürg Luterbacher (iD https://orcid.

org/0000-0002-8569-0973

Rob Allan (iD https://orcid.org/0000-0003-4065-6883

Dmytro Boichuk (D) https://orcid.org/0000-0003-4565-4887

Vladyslav Sidenko (D) https://orcid.

org/0000-0002-4143-2913

Olesya Skrynyk iD https://orcid.org/0000-0003-0332-5073

Angelika Palarz (D) https://orcid.org/0000-0002-5749-2507

Dmytro Oshurok (D) https://orcid.org/0000-0003-1192-3823

Elena Xoplaki (D) https://orcid.org/0000-0002-2745-2467

Volodymyr Osadchyi (iD https://orcid.

org/0000-0002-0428-4827

\section{REFERENCES}

Alcoforado, M.J., Vaquero, J.M., Trigo, R.M. and Taborda, J.P. (2012) Early Portuguese meteorological measurements (18th century). Climate of the Past, 8, 353-371. https://doi.org/10.5194/cp-8-353-2012

Allan, R., Brohan, P., Compo, G.P., Stone, R., Luterbacher, J. and Brönnimann, S. (2011) The international atmospheric circulation reconstructions over the earth (ACRE) initiative. Bulletin of the American Meteorological Society, 92, 1421-1425. https://doi. org/10.1175/2011BAMS3218.1

Ashcroft, L., Coll, J.R., Gilabert, A., Domonkos, P., Brunet, M., Aguilar, E. et al. (2018) A rescued dataset of sub-daily meteorological observations for Europe and the southern Mediterranean region, 1877-2012. Earth System Science Data, 10(3), 1613-1635. https:// doi.org/10.5194/essd-10-1613-2018

Ashcroft, L., Gergis, J. and Karoly, D.J. (2014) A historical climate dataset for southeastern Australia, 1788-1859. Geoscience Data Journal, 1, 158-178. https://doi.org/10.1002/gdj3.19
Auer, I., Böhm, R., Jurkovic, A., Lipa, W., Orlik, A., Potzmann, R. et al. (2007) HISTALP — historical instrumental climatological surface time series of the Greater Alpine Region. International Journal of Climatology, 27, 17-46. https://doi.org/10.1002/joc.1377

Boichuk, D., Skrynyk, O.A., Sidenko, V., Aguilar, E. and Skrynyk, O.Y. (2019) Extreme air temperature in Ukraine: data rescue, homogenization and trend analysis. Vienna, Austria: General Assembly of the European Geosciences Union.

Brázdil, R., Dobrovolny, P., Luterbacher, J., Moberg, A., Pfister, C., Wheeler, D. et al. (2010) European climate of the past 500 years: new challenges for historical climatology. Climatic Change, 101, 7-40. https://doi.org/10.1007/s10584-009-9783-z

Brönnimann, S., Allan, R., Ashcroft, L., Baer, S., Barriendos, M., Brázdil, R. et al. (2019) Unlocking pre-1850 instrumental meteorological records: a global inventory. Bulletin of the American Meteorological Society, 100, ES389-ES413. https://doi. org/10.1175/BAMS-D-19-0040.1

Brönnimann, S., Allan, R., Atkinson, C., Buizza, R., Bulygina, O., Dahlgren, P. et al. (2018a) Observations for Reanalyses. Bulletin of the American Meteorological Society, 99, 1851-1866. https://doi. org/10.1175/BAMS-D-17-0229.1

Brönnimann, S., Annis, J., Dann, W., Ewen, T., Grant, A.N., Griesser, T. et al. (2006) A guide for digitizing manuscript climate data. Climate of the Past, 2, 137-144. https://doi.org/10.5194/cp-2-137-2006

Brönnimann, S., Brugnara, Y., Allan, R.J., Brunet, M., Compo, G.P., Crouthamel, R.I. et al. (2018b) A roadmap to climate data rescue services. Geoscience Data Journal, 5, 28-39. https://doi. org/10.1002/gdj3.56

Brönnimann, S. and Wintzer, J. (2019) Climate data empathy. WIREs Climate Change, 10, e559. https://doi.org/10.1002/wcc.559

Brugnara, Y., Auchmann, R., Brönnimann, S., Allan, R.J., Auer, I., Barriendos, M. et al. (2015) A collection of sub-daily pressure and temperature observations for the early instrumental period with a focus on the "year without a summer" 1816. Climate of the Past, 11, 1027-1047. https://doi.org/10.5194/cp-11-1027-2015

Brunet, M., Brugnara, Y., Noone, S., Stephens, A., Valente, M.A., Ventura, C. et al. (2020) Best practice guidelines for climate data and metadata formatting, quality control and submission. Copernicus. Reading, UK: Copernicus Climate Change Service, p. 64.

Brunet, M., Gilabert, A., Jones, P. and Efthymiadis, D. (2014) A historical surface climate dataset from station observations in Mediterranean North Africa and Middle East areas. Geoscience Data Journal, 1, 121-128. https://doi.org/10.1002/gdj3.12

Brunet, M. and Jones, P. (2011) Data rescue initiatives: bringing historical climate data into the 21 st century. Climate Research, 47, 29-40. https://doi.org/10.3354/cr00960

Camuffo, D. and Bertolin, C. (2012) The earliest temperature observations in the world: the Medici Network (1654-1670). Climatic Change, 111, 335-363. https://doi.org/10.1007/s1058 4-011-0142-5

Camuffo, D., Bertolin, C., Diodato, N., Cocheo, C., Barriendos, M., Dominguez-Castro, F. et al. (2013) Western Mediterranean precipitation over the last 300 years from instrumental observations. Climatic Change, 117, 85-101. https://doi.org/10.1007/s1058 4-012-0539-9

Camuffo, D., della Valle, A., Bertolin, C. and Santorelli, E. (2017) Temperature observations in Bologna, Italy, from 1715 to 1815: a comparison with other contemporary series and an overview of three centuries of changing climate. Climatic Change, 142, 7-22. https://doi.org/10.1007/s10584-017-1931-2 
Camuffo, D., dellaValle, A., Becherini, F. and Zanini, V. (2020). Three centuries of daily precipitation in Padua, Italy, 1713-2018: history, relocations, gaps, homogeneity and raw data. Climatic Change. http://dx.doi.org/10.1007/s10584-020-02717-2

Craig, P. M. and Hawkins E. (2020). Digitizing observations from the Met Office Daily Weather Reports for 1900-1910 using citizen scientist volunteers. Geoscience Data Journal. http://dx.doi. org/10.1002/gdj3.93

Domínguez-Castro, F., Vaquero, J.M., Rodrigo, F.S., Farrona, A.M.M., Gallego, M.C., García-Herrera, R. et al. (2014) Early Spanish meteorological records (1780-1850). International Journal of Climatology, 34, 593-603. https://doi.org/10.1002/joc.3709

EuMetNet-DARE. (2018) Available at: https://www.zamg.ac.at/dare [Accessed 16 June 2020].

Hartmann, D.L., Klein Tank, A.M.G., Rusticucci, M., Alexander, L.V., Brönnimann, S., Charabi, Y. et al. (2013) Observations: atmosphere and surface. In: Stocker, T.F., Qin, D., Plattner, G.-K., Tignor, M., Allen, S.K., Boschung, J., Nauels, A., Xia, Y., Bex, V. and Midgley, P.M. (Eds.) Climate Change: The Physical Science Basis. Contribution of Working Group I to the Fifth Assessment Report of the Intergovernmental Panel on Climate Change. Cambridge and New York: Cambridge University Press, pp. 1- 1535. www.clima techange2013.org, www.ipcc.ch

Hawkins, E., Burt, S., Brohan, P., Lockwood, M., Richardson, H., Roy, M. and Thomas, S. (2019). Hourly weather observations from the Scottish Highlands (1883-1904) rescued by volunteer citizen scientists. Geoscience Data Journal, 6(2), 160-173. http://dx.doi. org/10.1002/gdj3.79

I-DARE (2019) Available at: https://www.idare-portal.org/content/inter national-data-rescue-i-dare-portal [Accessed 16 June 2020].

KHMO (Kiev Hydrometeorological Observatory) (1968) Climatological Handbook USSR, Issue 10, Ukrainian SSR "History and PhysicoGeographical Description of Meteorological Stations". Kiev: KHMO, p. 456 (in Russian).

Kwok, R. (2017) Hidden in the past. Nature, 549, 419-422. https://doi. org/10.1038/nj7672-419

Lamb, H.H. (1986) Ancient units used be pioneers of meteorological measurements. Weather, 41, 230-233. https://doi. org/10.1002/j.1477-8696.1986.tb03842.x

Luterbacher, J., Dietrich, D., Xoplaki, E., Grosjean, M. and Wanner, H. (2004) European seasonal and annual temperature variability, trends, and extremes since 1500. Science, 303, 1499-1503. https:// doi.org/10.1126/science.1093877

Luterbacher, J. and Pfister, C. (2015) The year without a summer. Nature Geoscience, 8, 246-248. https://doi.org/10.1038/ngeo2404

MEDARE (2007) WMO initiative. Available at: http://www.omm.urv. cat/MEDARE [Accessed 16 June 2020].

Mestre, O.andAguilar, E. (2011) HOME_R. Fast documentation. HOMER Training School, 36 pp. Available at: http://www.c3.urv. cat/data/HOME_R.pdf [Accessed 16 June 2020].

Mestre, O., Domonkos, P., Picard, F., Auer, I., Robin, S., Lebarbier, E. et al. (2013) HOMER: a homogenization software - methods and applications. Idojaras, 117, 47-67.

NOAA (National Oceanic and Atmospheric Administration) (2019) Old Weather. Available at: https://www.oldweather.org/index.html [Accessed 16 June 2020].

Osadchyi, V.I., Babichenko, V.M., Nabyvanets, Y.B. and Skrynyk, O.Y. (2013) Dynamics of Air Temperature in Ukraine over Instrumental Observation Period. Kyiv: Nika-Center, 308 pp. (in Ukrainian). ISBN: 978-966-521-348-2.
Osadchyi, V., Skrynyk, O.A., Radchenko, R. and Skrynyk, O.Y. (2018) Homogenization of Ukrainian air temperature data. International Journal of Climatology, 38, 497-505. https://doi.org/10.1002/joc.5191

Pfister, L., Hupfer, F., Brugnara, Y., Munz, L., Villiger, L., Meyer, L., Schwander, M., Isotta, F,A., Rohr, C. and Brönnimann, S. (2019). Early instrumental meteorological measurements in Switzerland. Climate of the Past, 15(4), 1345-1361. http://dx.doi.org/10.5194/cp-15-1345-2019

Raible, C.C., Brönnimann, S., Auchmann, R., Brohan, P., Frölicher, T., Graf, H.F. et al. (2016) Tambora 1815 as a test case for high impact volcanic eruption: Earth system effects. WIREs Climate Change, 7 , 569-589. https://doi.org/10.1002/wcc.407

Rodrigo, F. S. (2020). Recovering Climate Data from Documentary Sources: A Study on the Climate in the South of Spain from 1792 to 1808. Atmosphere, 11(3), 296. http://dx.doi.org/10.3390/atmos11030296

Shostin, N.A. (1975) Essays of Russian metrology history. Since XI until the beginning of XX centuries. Publishing of Standards. 272 p. (In Rusian).

Skrynyk, O.Y., Aguilar, E., Skrynyk, O.A., Sidenko, V., Boichuk, D. and Osadchyi, V. (2019) Quality control and homogenization of monthly extreme air temperature of Ukraine. International Journal of Climatology, 39, 2071-2079. https://doi.org/10.1002/joc.5934

Slonosky, V. (2014) Historical climate observations in Canada: 18th and 19 th century daily temperature from the St. Lawrence Valley. Quebec. Geoscience Data Journal 1, 103-120. https://doi.org/10.1002/gdj3.11

URHMI (Ukrainian Research Hydrometeorlogical Institute) (1953) Meteorological Data for Separate Years. Issue 10a. Ukrainian SSR and Moldavian SSR. Part 1. Air Temperature. Kiev: Publishing of Academy of Science of USSR, 577 pp. (in Russian).

URHMI (Ukrainian Research Hydrometeorlogical Institute) (1970) Hydrometeorological Service of Ukraine during 50 years of Soviet Power. Proceeding of UHMRI. Issue 81. Leningrad: Hydrometizdat. 271 p. (In Ukrainian).

Wilkinson, C., Brönnimann, S., Jourdain, S., Roucaute, E., Crouthamel, R., IEDRO Team et al. (2019) Best practice guidelines for climate data rescue. Copernicus Climate Change Service: Copernicus, p. 37.

WMO (World Meteorological Organization) (1989) Calculation of monthly and annual 30-years standard normals. WCDP 10, WMO-TD 341, World Meteorological Organization, World Climate Data and Monitoring Programme SeriesWashington D.C.

WMO (World Meteorological Organization) (2016) Guidelines on best practices for climate data rescue. WMO-No. 1182, pp. 30. Geneva: WMO.

Xoplaki, E., Luterbacher, J., Paeth, H., Dietrich, D., Steiner, N., Grosjean, M. et al. (2005) European spring and autumn temperature variability and change of extremes over the last half millennium. Geophysical Research Letters, 32, L15713. https://doi.org/10.1029/2005GL023424

\section{SUPPORTING INFORMATION}

Additional supporting information may be found online in the Supporting Information section.

How to cite this article: Skrynyk O, Luterbacher J, Allan R, et al. Ukrainian early (pre-1850) historical weather observations. Geosci Data J. 2021;8:55-73. https://doi.org/10.1002/gdj3.108 